\title{
The clinical spectrum and natural history of early-onset diseases due to DNA polymerase gamma mutations
}

Running title: Early onset POLG disease.

Omar Hikmat ${ }^{1,2}$ MD, Charalampos Tzoulis ${ }^{2,3}$ MD, PhD, Wui K. Chong ${ }^{4}$ FRCR, Latifa Chentouf ${ }^{5,6}$ BA(Hons), Claus Klingenberg ${ }^{7,8}$ MD, PhD, Carl Fratter ${ }^{9}$ MPhil, Lucinda J. Carr ${ }^{10}$ MD, Prab Prabhakar ${ }^{10}$ MBBS, Nandhini Kumaraguru ${ }^{11}$ MBBS, Paul Gissen ${ }^{6}$ FRCPCH, PhD, J. Helen Cross ${ }^{10,12}$ FRCP, PhD, Thomas S. Jacques ${ }^{13,14}$ FRCPath, PhD, Jan-Willem Taanman ${ }^{15} \mathrm{PhD}$, Laurence A. Bindoff ${ }^{2,3} \mathrm{MD}, \mathrm{PhD}$ and Shamima Rahman ${ }^{5,6} \mathrm{FRCP}, \mathrm{PhD}$.

1. Department of Pediatrics, Haukeland University Hospital, Bergen, Norway.

2. Department of Clinical Medicine (K1), University of Bergen, Norway.

3. Department of Neurology, Haukeland University Hospital, Bergen, Norway.

4. Department of Radiology, Great Ormond Street Hospital for Children NHS Foundation Trust, London, UK

5. Mitochondrial Research Group, UCL Great Ormond Street Institute of Child Health, London, UK.

6. Metabolic Unit, Great Ormond Street Hospital for Children NHS Foundation Trust, London, UK.

7. Department of Paediatric and Adolescent Medicine, University Hospital of North Norway, Tromso, Norway.

8. Paediatric Research Group, Department of Clinical Medicine, UiT- The Arctic University of Norway, Tromso, Norway.

9. Oxford Medical Genetics Laboratories, Oxford University Hospitals NHS Foundation Trust, Oxford, UK. 
10. Department of Neurology, Great Ormond Street Hospital for Children NHS Foundation Trust, London, UK.

11. Department of Paediatrics, Nottingham University Hospital NHS Trust, Nottingham, UK.

12. Clinical Neuroscience, UCL Great Ormond Street Institute of Child Health, London, UK.

13. Developmental Biology and Cancer Programme, UCL Great Ormond Street Institute of Child Health, UK.

14. Department of Histopathology, Great Ormond Street Hospital for Children NHS Foundation Trust, London, UK.

15. Department of Clinical Neurosciences, UCL Institute of Neurology, London, UK.

\section{Correspondence:}

Prof. Shamima Rahman

Mitochondrial Research Group, UCL Great Ormond Street Institute of Child Health, London WC1N 1EH, UK.

Metabolic Unit, Great Ormond Street Hospital, London, UK.

Telephone: +44 (0)20 79052608

shamima.rahman@ucl.ac.uk 


\begin{abstract}
Purpose:

Mutations in $P O L G$, the most common single gene cause of inherited mitochondrial disease are diagnostically challenging owing to clinical heterogeneity and overlap between syndromes. We aimed to improve the clinical recognition of $P O L G$-related disorders in the pediatric population.
\end{abstract}

\title{
Methods:
}

We performed a multinational, phenotype: genotype study using patients from three centers, two Norwegian and one from the UK. Patients with age of onset $<12$ years and confirmed pathogenic biallelic $P O L G$ mutations were considered eligible.

\section{Results:}

A total of 27 patients were identified with a median age at onset of 11 months (range 0.6 80.4). The majority presented with global developmental delay $(n=24 / 24,100 \%)$, hypotonia $(n=22 / 23,96 \%)$ and faltering growth $(n=24 / 27,89 \%)$. Epilepsy was common, but notably absent in patients with the myocerebrohepatopathy spectrum phenotype. We identified two novel $P O L G$ gene mutations.

\section{Conclusion:}

Our data suggest that $P O L G$-related disease should be suspected in any child presenting with diffuse neurological symptoms. Full $P O L G$ sequencing is recommended since targeted screening may miss mutations. Finally, we simplify the classification of $P O L G$ related disease in children using epilepsy as the crucial defining element; we show that Alpers and MCHS follow different outcomes and that they manifest different degrees of respiratory chain dysfunction. 
Keywords: Alpers, Infantile hepatocerebral syndromes, mitochondrial disease, mtDNA depletion, myocerebrohepatopathy syndrome, POLG. 


\section{INTRODUCTION}

POLG (OMIM *174763) encodes the catalytic subunit of DNA polymerase gamma, the enzyme responsible for mtDNA replication and repair. ${ }^{1}$ Mutations in $P O L G$ result in mtDNA depletion and/or multiple deletions and are considered the most common cause of inherited mitochondrial disorders. ${ }^{2,3}$

The first pathogenic $P O L G$ mutation was identified in families with autosomal dominant progressive external ophthalmoplegia (ADPEO). ${ }^{4}$ Subsequently, $P O L G$ mutations have been associated with a wide range of overlapping clinical phenotypes including: (a) Alpers syndrome, (b) myocerebrohepatopathy spectrum (MCHS), (c) myoclonic epilepsy, myopathy, sensory ataxia (MEMSA) - includes disorders previously described as spinocerebellar ataxia with epilepsy (SCAE), (d) ataxia neuropathy spectrum (ANS) including phenotypes previously described as sensory ataxia, neuropathy, dysarthria and ophthalmoplegia (SANDO) and mitochondrial recessive ataxia syndrome (MIRAS), (e) ADPEO, and (f) autosomal recessive PEO., ${ }^{5,6}$ are phenotypes include mitochondrial neurogastrointestinal encephalopathy (MNGIE)-like phenotype, ${ }^{7}$ mitochondrial encephalomyopathy, lactic acidosis and stroke-like episodes (MELAS)-like phenotype,${ }^{8}$ premature ovarian failure, ${ }^{9}$ parkinsonism, psychiatric disorders, cataract, ${ }^{10}$ sensorineural hearing loss, diabetes and cardiomyopathy. ${ }^{11}$

Alpers syndrome and MCHS are the two phenotypes most commonly reported with POLG mutations in the pediatric population. ${ }^{12}$ The neuropathology of Alpers syndrome (OMIM \# 203700) was first described in $1931,{ }^{13}$ but it was not until the 1980 s that the link to mitochondrial dysfunction was made. ${ }^{14}$ Pathogenic $P O L G$ mutations causing Alpers syndrome were first reported in $2004 .{ }^{15}$ This syndrome is almost universally fatal in childhood, making it one of the most severe forms in the spectrum of $P O L G$-related disease. 
Alpers syndrome is characterized by progressive encephalopathy with psychomotor regression, refractory epilepsy and characteristic liver disease,${ }^{16}$ presenting most frequently during infancy after an initial period of normal development. ${ }^{5,6}$ The most common early seizure types are focal and focal evolving to bilateral convulsive seizures, with predominance of epileptiform discharges over occipital regions. ${ }^{17}$ The seizure semiology may evolve with time to more complex forms including epilepsia partialis continua, myoclonic epilepsy and status epilepticus. ${ }^{17-19}$

Hepatic involvement may progress rapidly to end-stage liver failure, and may be triggered by valproic acid, ${ }^{20,21}$ but is not universal; affected children with biallelic $P O L G$ mutations with encephalopathy without liver failure are well recognised. ${ }^{11,19}$ Diagnostic criteria for Alpers syndrome include characteristic liver histopathological changes, namely two of: microvesicular steatosis, bile ductular proliferation, hepatocyte dropout, bridging fibrosis or cirrhosis, collapse of liver cell plates, parenchymal lobular architecture, regenerative nodules and oncocytic changes in scattered hepatocytes not affected by steatosis. ${ }^{12}$

MCHS is also severe and fatal, but less frequently reported than Alpers syndrome. MCHS most frequently presents between the neonatal period and three years and is characterized by a triad of myopathy or hypotonia, developmental delay or encephalopathy and liver dysfunction. ${ }^{12}$ Diagnostic criteria for MCHS include: absence of hepatic histopathological features of classical Alpers and at least two of the following: neuropathy, seizures, elevated blood or cerebrospinal fluid (CSF) lactate, dicarboxylic aciduria, renal tubular dysfunction with aminoaciduria, glycosuria or bicarbonaturia, hearing loss, abnormal MRI, with either cerebral volume loss, delayed myelination or white matter disease, and either isolated 
deficiency of complex IV (cytochrome $c$ oxidase) or a combined defect of two or more oxidative phosphorylation complexes in skeletal muscle or liver biopsy. $5,6,19,22,23$

MNGIE is a rare autosomal recessive mitochondrial disorder usually caused by mutations in TYMP encoding thymidine phosphorylase, an enzyme involved in nucleoside salvage.

MNGIE usually presents between the first and third decades with severe gastrointestinal dysmotility, failure to thrive, vomiting, abdominal pain, cachexia and neurological symptoms including encephalopathy, ptosis, ophthalmoplegia, peripheral neuropathy and muscle weakness. $^{24,25}$ POLG mutations have been previously reported in four patients (aged 15- 50 years) with a MNGIE-like phenotype., ${ }^{7,26}$

In this study we aimed to improve clinical recognition of the extremely heterogeneous and overlapping pediatric $P O L G$ phenotypes by carefully documenting and analysing the natural history of early onset $P O L G$-related disorders in a large multi-national pediatric cohort.

\section{PATIENTS AND METHODS}

\section{Study design and population:}

We conducted a multi-center, retrospective study including collaborating centers from Norway (Haukeland University Hospital, Bergen and University Hospital North of Norway, Troms $\varnothing$ ) and the United Kingdom (Great Ormond Street Hospital, London). All subjects with age of onset $<12$ years and biallelic pathogenic $P O L G$ variants were considered eligible. Patients who died before the $P O L G$ gene was identified were included if subsequent analysis of stored samples revealed two pathogenic $P O L G$ mutations. Deceased patients were included if an affected sibling had genetically confirmed $P O L G$-related disease and a similar clinical course. This study includes detailed clinical data of 13 patients (cases 1, 2, 3, 4, 9, 15, 
16,17,18,19, 20, 22 and 24, supplementary file 1) whose POLG mutations had been reported previously. ${ }^{27,28}$ Data collection was completed in July 2016.

Patients were phenotypically classified into three groups; Alpers spectrum, MCHS and MNGIE phenotypes, based on previously described criteria. ${ }^{12,23-25}$ In view of the rarity of MCHS, and to provide a better understanding of this particular phenotype, a systematic literature review (using search terms "POLG”, "mitochondria", "Alpers", "infantile hepatocerebral syndromes", "mtDNA depletion", "myocerebrohepatopathy syndrome" in PubMed, June 2016) was used to identify previously published cases. Cases with age of onset less than 12 years fulfilling the criteria for MCHS and confirmed bialleleic POLG mutations were included. These additional MCHS cases were not included in the natural history analysis.

\section{Data collection:}

Patient data (demographic information, clinical features, biochemical data, muscle biopsy, neurophysiological, neuroimaging and genetic findings, and medical treatment including response to anti-epileptic drugs) were collected using a structured electronic case report form which was developed and tested by a pilot study of 10 patients conducted in Haukeland University Hospital, Bergen, Norway.

Preterm birth was defined as birth before a gestational age of 37 completed weeks. Microcephaly was defined as head circumference more than two standard deviations below the mean for age and sex. Renal tubulopathy was defined by the presence of at least three of the following: tubular acidosis with generalised aminoaciduria, tubular proteinuria, glycosuria, Fanconi syndrome, or increase in urinary $\mathrm{N}$-acetyl-beta-D-glucosaminidase 
(NAG)/creatinine ratio. Liver involvement was defined by the presence of two or more of the following in at least two different time points; elevated aspartate aminotransferase (ASAT), gamma-glutamyltransferase (GGT), bilirubin or ammonia, low serum albumin, or pathological histological findings on liver biopsy. Hearing impairment was defined as abnormal auditory evoked response test. Neuroimaging was reviewed by two independent investigators. Therapy resistant epilepsy was defined using the International League Against Epilepsy (ILAE) definition. ${ }^{29}$

\section{Statistical analysis:}

Descriptive data analysis was performed using statistic software package SPSS version 23.0. End of follow-up was defined as the patient's last visit to the hospital or death. Univariate survival analysis was performed using log-rank test to compare differences in survival time between categories.

All genetic studies were performed with informed consent. Ethical approval for the study was obtained from the Regional Committee for Medical and Health Research Ethics, Western Norway (REK 2014/1783-4). The study was registered as an audit at Great Ormond Street Hospital, London, UK.

\section{RESULTS}

\section{Demography:}

Twenty-seven patients, (15 male, 12 female) from 22 pedigrees (including two patients from consanguineous families) with genetically confirmed $P O L G$ mutations were identified. Nineteen were diagnosed in the UK and eight in Norway. The majority of patients were 
Northern European ( $\mathrm{n}=23)$, with two patients from Cyprus, one from United Arab Emirates and one of Pakistani background (supplementary file 1).

\section{Major clinical features:}

Median age at onset of symptoms requiring medical evaluation for the group as a whole was 11.2 months (range 0.6 to 80.4 ). The majority of cases were born at term with uneventful pregnancy and delivery $(n=26)$; three cases were small for gestational age and one had microcephaly. Neonatal problems occurred in 11/27 (41\%) of cases, including feeding difficulties $(n=9 / 25,36 \%)$, vomiting $(n=7 / 21,33 \%)$, hypotonia $(n=4 / 23,17 \%)$, and hypoglycaemia $(\mathrm{n}=2 / 20,10 \%)$. None had neonatal seizures. Disease onset was apparently spontaneous in 15/26 (58\%) and followed an infectious illness in 11 cases (42\%).

The predominant clinical features (Table 1) were faltering growth $(n=24 / 27,89 \%)$, global developmental delay $(n=24 / 24,100 \%)$, hypotonia $(n=22 / 23,96 \%)$, seizures $(n=19 / 26,73 \%)$, and vomiting $(\mathrm{n}=22 / 26,85 \%)$. Focal evolving to bilateral convulsive seizures (Table 1$)$ were the most common seizure type $(n=14 / 19,74 \%)$. Infantile spasms were observed in one case (patient 23). Electroencephalogram (EEG) was pathological in 19 of 22 patients (Table 1) with epileptiform activities predominantly over occipital regions (Fig 1).

Renal tubular dysfunction was observed in three cases, and one child had hypothyroidism. Ophthalmological involvement occurred in 12 patients, including optic atrophy in two cases (patients 13 and 16) and cataract in another two cases (patients 19 and 20). Two children (patients 1 and 21) had hearing impairment.

\section{Biochemical, neurophysiological and muscle biopsy findings:}


Laboratory investigations at presentation revealed increased lactate in blood in $60 \%$ $(n=12 / 20)$ and in CSF in 40\% ( $n=2 / 5)$. Hepatic aminotransferases were increased in 13/20 cases (Table 1). Electromyogram and nerve conduction studies were performed on 6 cases and were abnormal in only one case, who had neuropathic and axonal changes. Visual evoked response was abnormal in 5 of 10 cases.

Muscle biopsy was performed in 14 cases, and was abnormal in 10 (Table 1): three had ragged red fibers (Figure 1) and four COX-negative fibers, excessive lipid accumulation was observed in 7 cases and abnormal respiratory chain activities in 9 cases (supplementary file 2). Interestingly, most Alpers patients had normal respiratory chain enzyme activities or isolated deficiency of a single enzyme complex, whilst those with MCHS had multiple respiratory chain complex deficiencies (supplementary file 2).

\section{Neuroimaging:}

Magnetic resonance images (MRI) were available for 17 cases. The majority ( $n=14 / 17,82 \%)$ showed abnormality at disease onset. The most common MRI finding was cortical focal lesions manifesting as T2/FLAIR hyperintensities involving cortical and subcortical areas, predominantly affecting the occipital lobes (Fig 1). Less frequently, T2-hyperintense thalamic lesions $(n=3 / 17,18 \%)$ and cerebellar atrophy $(n=1 / 17,6 \%)$ were observed (Table 1).

\section{Genetic findings:}

All cases had two confirmed pathogenic $P O L G$ variants identified either by targeted mutation analysis for specific common mutations (c.1399G>C, p.Ala467Thr and c.2243G>C, p.Trp748Ser) or by sequence analysis of all coding regions of POLG. Two novel POLG gene mutations (c.1493A>C, p.Lys498Thr, and c.1862 G>A, p.Gly621Asp) were identified (cases 
23 and 26). The c.2492A>G, p.Tyr831Cys change has a relatively high population frequency (0.006277; Exome Aggregation Consortium (ExAC), Cambridge, MA),${ }^{30}$ but when it occurs in trans with a severe mutation such as c.3401A >G, p.His1134Arg it is clearly pathogenic. All $P O L G$ mutations and associated phenotypes identified in this study are illustrated in figure 2.

\section{Phenotype spectrum:}

Six patients fulfilled diagnostic criteria for MCHS, 19 for Alpers and one for a MNGIE-like phenotype. One patient was unclassified owing to insufficient data. The median age at onset for the MCHS group was 4.7 months (range 0.9-7 months) compared to 12.4 months (range 0.9-80.4 months) for the Alpers group. All patients with MCHS had liver pathology, hypotonia and failure to thrive. None had seizures (Table 2). Five additional patients from the literature review fulfilling diagnostic criteria for MCHS ${ }^{19,22,31}$ had similar clinical features and also did not have seizures (Table 2). The common founder mutations c.1399G>C, p.Ala467Thr and c.2243G>C, p.Trp748Ser were present in one MCHS case in our cohort (case 16) and one case in the literature. All cases in our cohort fulfilling diagnostic criteria for Alpers syndrome had epilepsy (19/19). One patient was classified as having a MNGIE-like phenotype (case 27). This is a 7 year old boy, who presented at the age of 3 months with failure to thrive, progressive gastro-intestinal dysmotility, vomiting, and gradually became dependent on total parental nutrition. He has muscle weakness, absent lower limb reflexes and is wheelchair dependent. He is developmentally delayed and has learning difficulties. He has no liver pathology, seizures or leukoencephalopathy.

\section{Survival analysis:}

Of 27 patients, 4 were alive at the time of data analysis, and one had been lost to follow up. Median age at death was 15.8 months (range 1.0 to 184.6 months), whereas median time from 
disease onset to death was 4.9 months (range 0.5 to 181.2 months). The main causes of death were liver failure (13/22), sepsis (5/22) and status epilepticus (4/22). Median survival time of patients with disease onset $\leq 12$ months was 3.6 months ( range $0.5-181$ ) compared to 10 months (range 1.4-82) for those with disease onset $>12$ months. Further analysis showed that median survival time of patients with epilepsy was 4 months (range $0.5-181$ ), compared to 5 months (range 0.5-91) for those without epilepsy. Survival analysis by phenotype showed that the median survival time for patients with MCHS was 5 months (range 0.6-22) and 4 months (range 0.5-181) for Alpers.

\section{DISCUSSION}

Diagnosis of mitochondrial disorders is still a major challenge, particularly in the pediatric population. $P O L G$ mutations are associated with a wide and overlapping spectrum of phenotypes and while several major clinical entities are now recognized, it is likely that neither the full spectrum nor the extent to which the phenotypes overlap is yet known. ${ }^{5,6}$ Reports in adults of minor phenotypes such as MELAS-like, MNGIE-like, optic atrophy, diabetes, hearing loss, ${ }^{7,8,10,11}$ have added to the confusion. The cornerstone of clinical diagnosis is a relevant phenotypic classification that physicians in everyday clinical practice can use. We have therefore analysed the largest pediatric cohort to date to provide a comprehensive clinical description of pediatric patients with $P O L G$-related disease.

We found that the majority of patients had relatively diffuse clinical features with hypotonia, developmental delay, failure to thrive and seizures. These non-specific clinical features overlap with the manifestations of other mitochondrial disorders presenting during early childhood including: Alpers syndrome caused by defects in other genes (e.g. TWNK, FARS2, NARS2 and PARS2), ${ }^{32-36}$ and causes of Leigh syndrome such as SURF1 deficiency. ${ }^{37-39}$ 
Consequently, identifying which individuals to screen for $P O L G$ mutations in the neonatal period and early childhood is challenging. Further, our study showed that early onset $P O L G-$ related disorders are associated with high mortality $(n=22 / 26,85 \%)$. The elapsed median time from disease onset to death was 5 months, highlighting the rapid disease progression. As a result, early clinical recognition and diagnosis is particularly urgent, especially in families seeking prenatal diagnosis.

Epilepsy was one of the major clinical features, and was present in $89 \%(n=17 / 19)$ at disease onset. Seizure semiology was similar to that reported in adult onset $P O L G$-related disorders ${ }^{17,39}$ with predominance of focal and focal evolving to bilateral convulsive seizures and epileptiform discharges over occipital regions. Ataxia, movement disorders and stroke-like episodes were less frequent compared to adults with $P O L G$ mutations. Cataract and retinopathy have been reported in adults, ${ }^{10,18}$ but we now describe two pediatric patients with cataract and two with optic atrophy. Diabetes and cardiomyopathy were not present in our pediatric cohort. Despite the overlapping features between early and later onset $P O L G$-related disorders, it is clear from our study, and our literature review, that these two groups are not identical and we feel they should be considered as two separate entities.

Regarding phenotypic classification, our data reinforced the current understanding of Alpers and MCHS as two separate entities with different age of onset and survival. We found, however, significant overlap in clinical features between the Alpers and MCHS subgroups and application of the previously described criteria for diagnosis ${ }^{12,23}$ was challenging. Using the characteristic liver pathological findings to differentiate, as previously suggested, ${ }^{12}$ was not possible as liver biopsy was only performed in three of our cases. This likely reflects clinical practice where liver biopsy is rarely performed in the neonatal and pediatric setting, 
because of the attendant risks of morbidity and mortality. Moreover, not all patients with the Alpers phenotype even show liver enzyme abnormalities. By comparing our cohort of patients with Alpers and those with MCHS, we found, however, that epilepsy was exclusively associated with the Alpers phenotype (Table 3). To confirm this, we conducted a systematic literature review to identify previously published MCHS cases (Table 2), and found too that none of these had epilepsy. Further, the most severe respiratory chain defects were observed in the MCHS group, supporting the view that these patients are more severely affected and potentially die before the onset of seizures. Discordance observed in one sibling pair (cases 15 and 16) provides further evidence for this hypothesis. Case 15 died at 9 months with intractable seizures whereas his sister case 16 died at 5 months and never developed seizures. Based on our findings, we suggest that instead of using complicated clinical and histopathological criteria to differentiate between Alpers and MCHS phenotypes, the classification of early onset $P O L G$-related disorders can be simplified into those with or without epilepsy.

Our cohort also includes a patient with an early onset MNGIE-like phenotype without leukoencephalopathy (patient 27). This expands the phenotypic spectrum in this age group and demonstrates the importance of considering POLG-related disorders in children with severe gastrointestinal dysmotility even in the absence of liver pathology, seizures or characteristic neuro-radiological findings for $P O L G$ disease.

Previous reports have recommended screening for the common founder $P O L G$ mutations in children younger than 12 years with unexplained encephalopathy, or multi-system neurological disorders. ${ }^{11,40}$ Since these mutations (c.1399G>A, p.Ala467Thr and c.2243G>C, p.Trp748Ser) were identified only once in in our MCHS cohort (patient 16) and one 
previously published MCHS case,${ }^{31}$ there is a high risk of missing the diagnosis in these patients, demonstrating clearly the limited value of screening only for common POLG mutations in this age group.

In conclusion, while early onset $P O L G$-related disease is associated with complex overlapping phenotypes, we suggest classification can be simplified according to the presence or absence of epilepsy. We provide a detailed description of the natural history of early onset $P O L G$-related disorders, and a simplified classification to facilitate clinical recognition of these disorders by neonatologists and pediatricians. Furthermore, we demonstrate the need to perform full sequence analysis of the entire $P O L G$ gene rather than targeting common $P O L G$ mutations in patients with unexplained encephalopathy and multi-system disorders with or without epilepsy, both in the neonatal period and during childhood.

\section{Acknowledgements}

This work was supported by grants from the Western Norway Regional Health Authority. SR is supported by a Great Ormond Street Hospital Children's Charity Research Leadership Award (V1260) and her group currently receives research grant funding from the Lily Foundation and the National Institute for Health Research Biomedical Research Centre at Great Ormond Street Hospital for Children NHS Foundation Trust and University College London. We would like to thank the NHS England Rare Mitochondrial Disease Service laboratories in London and Newcastle for performing respiratory chain enzyme assays and Tom Eichele, Neurophysiology Department, Haukeland University Hospital, Bergen-Norway for help in reviewing EEG findings. 


\section{References:}

1. Copeland WC, Longley MJ. DNA polymerase gamma in mitochondrial DNA replication and repair. TheScientificWorldJournal. 2003;3:34-44.

2. Chinnery PF, Zeviani M. 155th ENMC workshop: polymerase gamma and disorders of mitochondrial DNA synthesis, 21-23 September 2007, Naarden, The Netherlands. Neuromuscular disorders : NMD. 2008;18(3):259-267.

3. Spinazzola A, Zeviani M. Disorders from perturbations of nuclear-mitochondrial intergenomic cross-talk. Journal of internal medicine. 2009;265(2):174-192.

4. Van Goethem G, Dermaut B, Lofgren A, Martin JJ, Van Broeckhoven C. Mutation of POLG is associated with progressive external ophthalmoplegia characterized by mtDNA deletions. Nature genetics. 2001;28(3):211-212.

5. Cohen BH, Chinnery PF, Copeland WC. POLG-Related Disorders. In: Pagon RA, Adam MP, Ardinger HH, et al., eds. GeneReviews(R). Seattle (WA): University of Washington, Seattle. All rights reserved.; 1993.

6. Saneto RP, Naviaux RK. Polymerase gamma disease through the ages. Developmental disabilities research reviews. 2010;16(2):163-174.

7. Tang S, Dimberg EL, Milone M, Wong LJ. Mitochondrial neurogastrointestinal encephalomyopathy (MNGIE)-like phenotype: an expanded clinical spectrum of POLG1 mutations. Journal of neurology. 2012;259(5):862-868.

8. Deschauer M, Tennant S, Rokicka A, et al. MELAS associated with mutations in the POLG1 gene. Neurology. 2007;68(20):1741-1742.

9. Pagnamenta AT, Taanman JW, Wilson CJ, et al. Dominant inheritance of premature ovarian failure associated with mutant mitochondrial DNA polymerase gamma. Human reproduction (Oxford, England). 2006;21(10):2467-2473. 
10. Luoma P, Melberg A, Rinne JO, et al. Parkinsonism, premature menopause, and mitochondrial DNA polymerase gamma mutations: clinical and molecular genetic study. Lancet (London, England). 2004;364(9437):875-882.

11. Horvath R, Hudson G, Ferrari G, et al. Phenotypic spectrum associated with mutations of the mitochondrial polymerase gamma gene. Brain : a journal of neurology. 2006;129(Pt 7):1674-1684.

12. Nguyen KV, Sharief FS, Chan SS, Copeland WC, Naviaux RK. Molecular diagnosis of Alpers syndrome. Journal of hepatology. 2006;45(1):108-116.

13. Alpers BJ. DIffuse progressive degeneration of the gray matter of the cerebrum. Archives of Neurology \& Psychiatry. 1931;25(3):469-505.

14. Gabreels FJ, Prick MJ, Trijbels JM, et al. Defects in citric acid cycle and the electron transport chain in progressive poliodystrophy. Acta neurologica Scandinavica. $1984 ; 70(3): 145-154$.

15. Naviaux RK, Nguyen KV. POLG mutations associated with Alpers' syndrome and mitochondrial DNA depletion. Annals of neurology. 2004;55(5):706-712.

16. Harding BN. Progressive neuronal degeneration of childhood with liver disease (Alpers-Huttenlocher syndrome): a personal review. Journal of child neurology. 1990;5(4):273-287.

17. Engelsen BA, Tzoulis C, Karlsen B, et al. POLG1 mutations cause a syndromic epilepsy with occipital lobe predilection. Brain : a journal of neurology. 2008;131(Pt 3):818-828.

18. Hakonen AH, Heiskanen S, Juvonen V, et al. Mitochondrial DNA polymerase W748S mutation: a common cause of autosomal recessive ataxia with ancient European origin. American journal of human genetics. 2005;77(3):430-441. 
19. de Vries MC, Rodenburg RJ, Morava E, et al. Multiple oxidative phosphorylation deficiencies in severe childhood multi-system disorders due to polymerase gamma (POLG1) mutations. European journal of pediatrics. 2007;166(3):229-234.

20. Saneto RP, Lee IC, Koenig MK, et al. POLG DNA testing as an emerging standard of care before instituting valproic acid therapy for pediatric seizure disorders. Seizure. 2010;19(3):140-146.

21. Tzoulis C, Engelsen BA, Telstad W, et al. The spectrum of clinical disease caused by the A467T and W748S POLG mutations: a study of 26 cases. Brain : a journal of neurology. 2006;129(Pt 7):1685-1692.

22. Ferrari G, Lamantea E, Donati A, et al. Infantile hepatocerebral syndromes associated with mutations in the mitochondrial DNA polymerase-gammaA. Brain : a journal of neurology. 2005;128(Pt 4):723-731.

23. Wong LJ, Naviaux RK, Brunetti-Pierri N, et al. Molecular and clinical genetics of mitochondrial diseases due to POLG mutations. Human mutation. 2008;29(9):E150172.

24. Nishino I, Spinazzola A, Papadimitriou A, et al. Mitochondrial neurogastrointestinal encephalomyopathy: an autosomal recessive disorder due to thymidine phosphorylase mutations. Annals of neurology. 2000;47(6):792-800.

25. D'Angelo R, Rinaldi R, Carelli V, et al. ITA-MNGIE: an Italian regional and national survey for mitochondrial neuro-gastro-intestinal encephalomyopathy. Neurological sciences : official journal of the Italian Neurological Society and of the Italian Society of Clinical Neurophysiology. 2016;37(7):1149-1151.

26. Van Goethem G, Schwartz M, Lofgren A, Dermaut B, Van Broeckhoven C, Vissing J. Novel POLG mutations in progressive external ophthalmoplegia mimicking 
mitochondrial neurogastrointestinal encephalomyopathy. European journal of human genetics : EJHG. 2003;11(7):547-549.

27. Taanman JW, Rahman S, Pagnamenta AT, et al. Analysis of mutant DNA polymerase gamma in patients with mitochondrial DNA depletion. Human mutation. $2009 ; 30(2): 248-254$.

28. Tzoulis C, Neckelmann G, Mork SJ, et al. Localized cerebral energy failure in DNA polymerase gamma-associated encephalopathy syndromes. Brain : a journal of neurology. 2010;133(Pt 5):1428-1437.

29. Kwan P, Arzimanoglou A, Berg AT, et al. Definition of drug resistant epilepsy: consensus proposal by the ad hoc Task Force of the ILAE Commission on Therapeutic Strategies. Epilepsia. 2010;51(6):1069-1077.

30. Lek M, Karczewski KJ, Minikel EV, et al. Analysis of protein-coding genetic variation in 60,706 humans. Nature. 2016;536(7616):285-291.

31. Tang S, Wang J, Lee NC, et al. Mitochondrial DNA polymerase gamma mutations: an ever expanding molecular and clinical spectrum. Journal of medical genetics. 2011;48(10):669-681.

32. Rotig A, Poulton J. Genetic causes of mitochondrial DNA depletion in humans. Biochimica et biophysica acta. 2009;1792(12):1103-1108.

33. Nikali K, Lonnqvist T. Infantile-Onset Spinocerebellar Ataxia. In: Pagon RA, Adam MP, Ardinger HH, et al., eds. GeneReviews $(R)$. Seattle (WA): University of Washington, Seattle. All rights reserved.; 1993.

34. Elo JM, Yadavalli SS, Euro L, et al. Mitochondrial phenylalanyl-tRNA synthetase mutations underlie fatal infantile Alpers encephalopathy. Human molecular genetics. 2012;21(20):4521-4529. 
35. Sofou K, Kollberg G, Holmstrom M, et al. Whole exome sequencing reveals mutations in NARS2 and PARS2, encoding the mitochondrial asparaginyl-tRNA synthetase and prolyl-tRNA synthetase, in patients with Alpers syndrome. Molecular genetics \& genomic medicine. 2015;3(1):59-68.

36. Vanlander AV, Menten B, Smet J, et al. Two siblings with homozygous pathogenic splice-site variant in mitochondrial asparaginyl-tRNA synthetase (NARS2). Human mutation. 2015;36(2):222-231.

37. Sofou K, De Coo IF, Isohanni P, et al. A multicenter study on Leigh syndrome: disease course and predictors of survival. Orphanet journal of rare diseases. 2014;9:52.

38. Wedatilake Y, Brown RM, McFarland R, et al. SURF1 deficiency: a multi-centre natural history study. Orphanet journal of rare diseases. 2013;8:96.

39. Wolf NI, Rahman S, Schmitt B, et al. Status epilepticus in children with Alpers' disease caused by POLG1 mutations: EEG and MRI features. Epilepsia. 2009;50(6):1596-1607.

40. Hakonen AH, Davidzon G, Salemi R, et al. Abundance of the POLG disease mutations in Europe, Australia, New Zealand, and the United States explained by single ancient European founders. European journal of human genetics : EJHG. 2007;15(7):779-783. 


\section{Figure legends:}

Figure 1. Upper panel: EEG traces and MRI scans recorded during the same period of hospitalization in two patients with Alpers syndrome caused by $P O L G$ mutations.

A (case 2): EEG tracing displayed at 30mm/cm, $150 \mu \mathrm{V} / \mathrm{cm}, 0.01-30 \mathrm{~Hz}$. EEG shows high voltage polyspike-slow and sharp-slow wave around $1-2 \mathrm{~Hz}$ frequency in the right occipitotemporal channels. Axial T2-weighted MRI shows bilateral high T2 signal consistent with cortical edema, in the occipitotemporal regions.

B (case 4): EEG tracing displayed at $30 \mathrm{~mm} / \mathrm{cm}, 500 \mu \mathrm{V} / \mathrm{cm}$, and $0.01-30 \mathrm{~Hz}$. Periodic polyspike-slow waves localized at the left occipitotemporal area. Axial T2-weighted MRI shows bilateral cortical edema, in the occipitotemporal regions.

Lower panel: Muscle histochemistry from three cases shows occasional fibres with dense mitochondrial accumulations on the Gömöri trichrome stain (a case 17, b case 18, and c case 4). In a few fibres, these formed subsarcolemmal accumulations that indented the sarcoplasm on at least two sides as seen typically in ragged red fibres $(a, b)$.

Figure 2. Schematic diagram of the $P O L G$ gene illustrating mutations identified in this study. Mutations associated with the Alpers and MCHS phenotypes are located throughout the gene, i.e. in the exonuclease, linker and polymerase domains. The mutations in the patient with a MNGIE-like phenotype were also present in patients with Alpers and MCHS. 


\section{Tables legends:}

Table 1. Major clinical, laboratory, electroencephalography (EEG), and neuroimaging findings.

Table 2. Summary of the clinical and genetic findings for patients with MCHS included in this study and those reported in the literature.

Table 3. Comparison between patients with MCHS and Alpers phenotypes included in the study cohort 
$-\mathrm{A}$

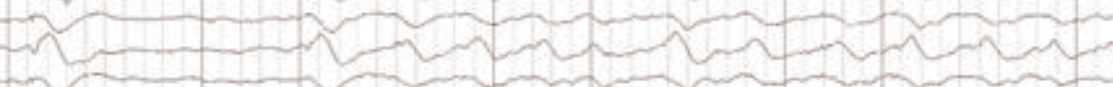
(n) 1014 mi C.n. $\ln _{0}$ $+1$ 군 $\rightarrow \rightarrow-1+m$
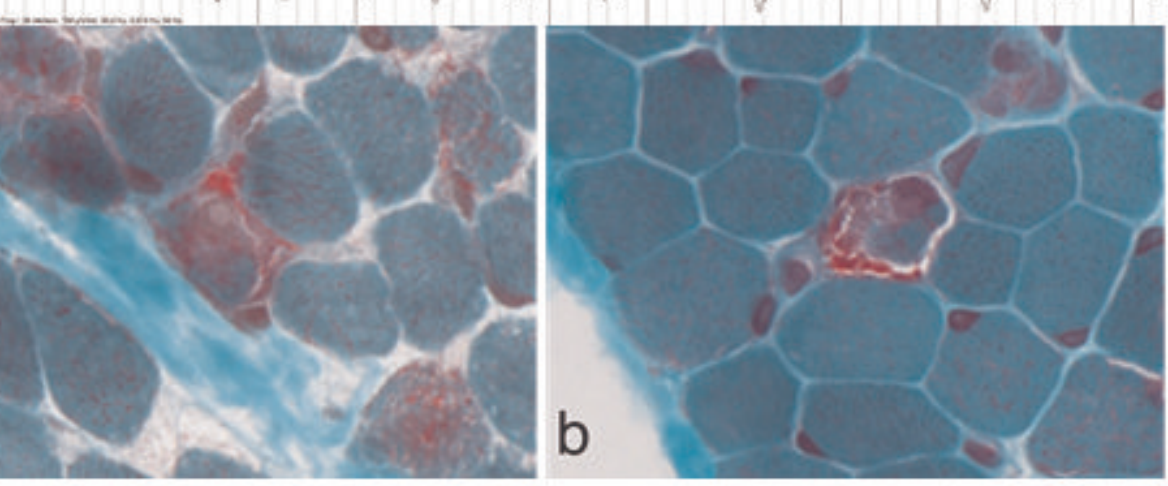
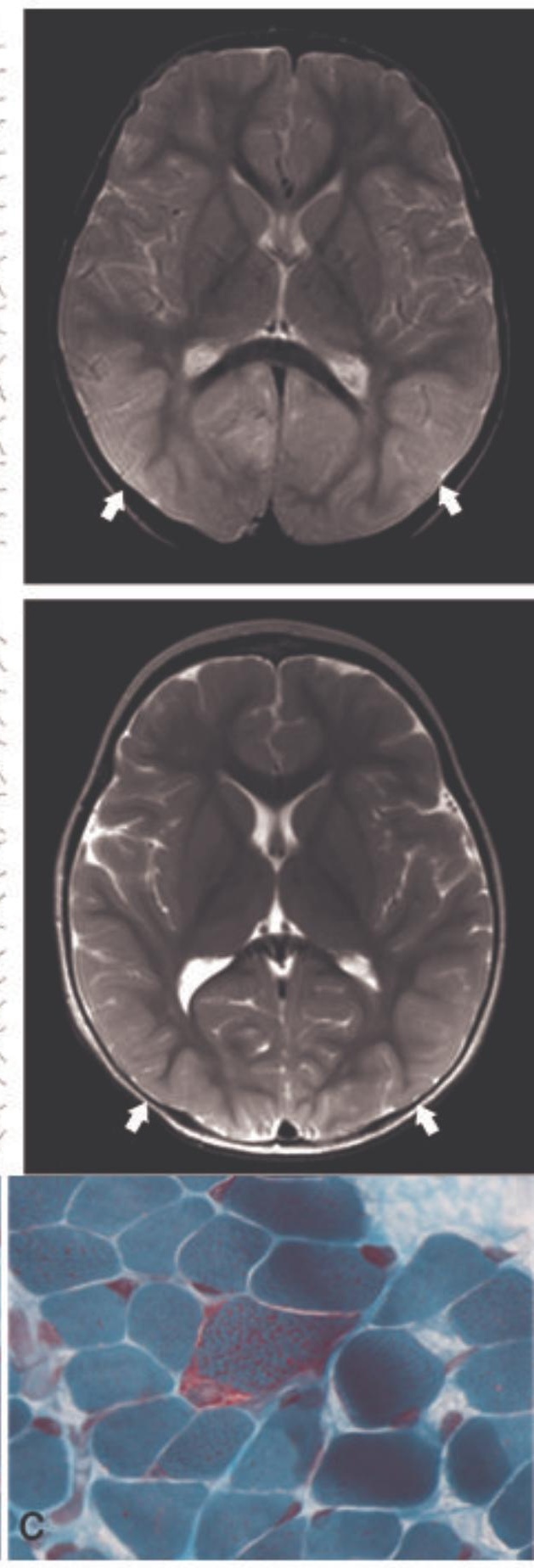


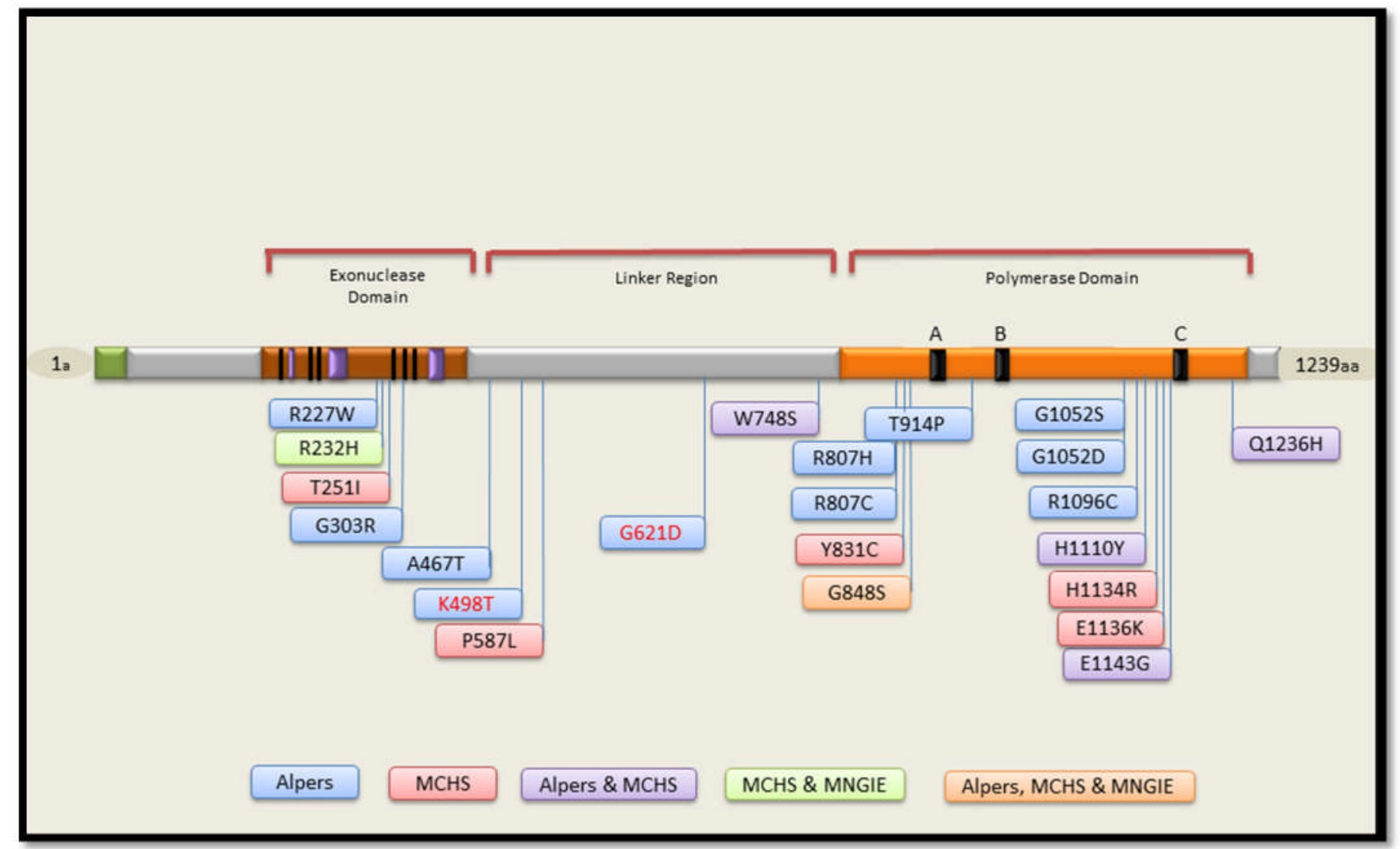

Figure 2. Schematic diagram of the POLG gene illustrating mutations identified in this study. Mutations associated with the Alpers and MCHS phenotypes are located throughout the gene, i.e. in the exonudease, linker and polymerase domains. The mutations in the patient with a MNGIE-like phenotype were also present in patients with Alpers and MCHS. The E1143G and Q1236H that not considered definitely pathological are associated with other known pathogenic mutations. The novel mutations identified in this study are in red. 
Table 1 Major dinical, laboratory, electroencephalography (匟), and neuroimaging findings

\begin{tabular}{ccc}
\hline A. Cinical features & $\begin{array}{c}\text { Number of patients } \\
\text { at onset }\end{array}$ & $\begin{array}{c}\text { Number of patients chring disease } \\
\text { course }\end{array}$ \\
\hline
\end{tabular}

1- Neurological $(n=27 / 27)$

Seizures

$17 / 19$

19/26(73\%)

- Primary generalized tonic-clonic

none

- Myodonic

$13 / 19(68 \%)$

- Status epilepticus

$13 / 19(68 \%)$

- Epilepsia partialis continua

$11 / 19(58 \%)$

- Focal evolving to bilateral convulsive

$14 / 19$ (74\%)

- Focal

$14 / 19(74 \%)$

- Infantile spasm

$1 / 19(5 \%)$

- Therapy resistant epilepsy

$17 / 19(89 \%)$

Stroke-like episodes

$2 / 5$

Hypotonia

$22 / 22$

$5 / 18(28 \%)$

Ataxia

$0 / 12$

22/23(96\%)

Dystonia

$2 / 3$

$2 / 14(14 \%)$

Hearing impairment

$2 / 2$

$3 / 24(12 \%)$

2/20 (10\%)

2- Ophthalmological $(n=12 / 23)$

Ptosis

none

none

Progressive external ophthalmoplegia

none

none

Cataract

$2 / 2$

2/23(9\%)

Optic atrophy

$2 / 2$

$2 / 23(9 \%)$

Visual impairment not classified

$2 / 4$

$4 / 23(17 \%)$

Nystagmus

$2 / 6$

$6 / 23(26 \%)$

3-Gastro-intestinal $(n=25 / 27)$

Faltering growth

$22 / 24$

$24 / 27(89 \%)$

Vomiting

$18 / 22$

$22 / 26$ (85\%)

Liver dysfunction

$14 / 23$

$23 / 25(92 \%)$

Chronic diarrhea

$1 / 1$

$1 / 17 \quad(6 \%)$

4-Endocrine $(n=4 / 27)$

Diabetes mellitus

none

none

Hypoglycemia

2/3

3/27 (11\%)

Hypoparathyroidism

$1 / 1$

$1 / 27(4 \%)$

Hypothyroidism

$1 / 1$

$1 / 27(4 \%)$

Growth hormone deficiency

none

none

5-Renal $(n:=3 / 7)$

Renal tubular dysfunction 


\section{1-Blood:}

Elevate lactate

$12 / 20$

Elevated creatine kinase

$1 / 5$

Low albumin

$14 / 20$

Elevated aspartate aminotransferase

$13 / 20$

Elevated alanine aminotransferase

$7 / 14$

Elevated gamma glutamyl transferase

$9 / 10$

\section{2-Cerebrospinal fiuid}

Elevated lactate

2/5

Elevated protein

$11 / 14$

\section{3-Musde biopsy:}

Pathological finding

$10 / 14$

Red - ragged fibers

$3 / 14$

COX-negative fibers

$4 / 14$

Excessive fluid accumulation

$7 / 14$

Abnormal respiratory chain activities

9/14

\section{EG findings- epileptiformadivities}

in:

Frontal lobe

$4 / 19(21 \%)$

Parietal lobe

$4 / 19(21 \%)$

Temporal lobe

$2 / 19(10 \%)$

Occipital lobe

$10 / 19(53 \%)$

Multifocal

$7 / 19(37 \%)$

\section{Magnetic resonance imaging(MRI) findings}

MRI lesions at onset

MRI lesions during disease course

General cerebral atrophy

CFLfrontal lobe

CFL parietal /temporal lobe

CFL occipital lobe

White matter lesions

Thalamus

Cerebellumatrophy
14/17 (82\%)

$15 / 17(88 \%)$

$4 / 17(23 \%)$

$4 / 17(23 \%)$

$3 / 17(18 \%)$

$6 / 17(35 \%)$

$5 / 17(29 \%)$

$3 / 17(18 \%)$

$1 / 17(6 \%)$

CFL: cortical focal lesions 
Table 2. Summary of the clinical and genetic findings for patients with MCHS included in this study and those reported in the literature

\begin{tabular}{|c|c|c|c|c|c|c|c|c|c|c|c|}
\hline $\begin{array}{l}\text { Casestudy } \\
\text { number }\end{array}$ & $\begin{array}{l}\text { Age of } \\
\text { onset }\end{array}$ & Hypotonia & $\begin{array}{l}\text { Developmental } \\
\text { delay }\end{array}$ & Epilepsy & $\begin{array}{l}\text { Faltering } \\
\text { growth }\end{array}$ & $\begin{array}{c}\text { Liver } \\
\text { dysfundion }\end{array}$ & $\begin{array}{c}\text { Hypo- } \\
\text { gycemia }\end{array}$ & $\begin{array}{c}\text { Renal } \\
\text { dysfunction }\end{array}$ & $\begin{array}{l}\text { Ophthalmological } \\
\text { disorder }\end{array}$ & $\begin{array}{l}\text { Cause of } \\
\text { death }\end{array}$ & Mutations \\
\hline 8 & $5 \mathrm{~m}$ & + & + & - & + & + & - & - & $\begin{array}{l}\text { Optic atrophy, } \\
\text { nystagmus }\end{array}$ & $\begin{array}{l}\text { Liver } \\
\text { failure } \\
\text { Liver }\end{array}$ & $\begin{array}{l}\text { His1110Tyr+Gln1236His/ } \\
\text { Trp748Ser+Glu1143Gly } \\
\text { Arq232His/Gly848Ser }\end{array}$ \\
\hline 9 & $7 \mathrm{~m}$ & + & + & - & + & + & + & - & & $\begin{array}{l}\text { failure } \\
\text { Liver }\end{array}$ & Arg232His/Gly848Ser \\
\hline 10 & $6 m$ & + & + & - & + & + & - & - & & $\begin{array}{l}\text { failure } \\
\text { Liver }\end{array}$ & Thr251Ile+Pro587Leu/ \\
\hline 11 & $3 m$ & + & + & - & + & + & + & + & Cataract & $\begin{array}{l}\text { failure } \\
\text { Liver }\end{array}$ & $\begin{array}{c}\text { Glu1136Lys } \\
\text { Thr251lle+Pro587Leu/ }\end{array}$ \\
\hline 12 & $4 m$ & + & + & - & + & + & + & + & $\begin{array}{l}\text { Cataract } \\
\text { Visual }\end{array}$ & $\begin{array}{l}\text { failure } \\
\text { Liver }\end{array}$ & $\begin{array}{c}\text { Glu1136Lys } \\
\text { Tyr831Cys/ His1134Arg }\end{array}$ \\
\hline 15 & $1 \mathrm{~m}$ & + & + & - & + & + & - & + & impairment & failure & \\
\hline \multicolumn{12}{|c|}{$\begin{array}{l}\text { Previously reported } \\
\text { (Reference) }\end{array}$} \\
\hline$A(22)$ & $3 \mathrm{~m}$ & + & + & - & + & + & + & - & - & $\begin{array}{l}\text { Liver } \\
\text { failure } \\
\text { Liver }\end{array}$ & $\begin{array}{l}\text { Thr251lle/ Pro587Leu } \\
\text { Arg232His/Asp1184Asn }\end{array}$ \\
\hline$B(19)$ & $7 \mathrm{~m}$ & + & + & - & + & + & NA & + & - & $\begin{array}{l}\text { failure } \\
\text { Liver }\end{array}$ & Arg232His/Asp1184Asn \\
\hline$C(19)$ & $4 m$ & + & + & - & + & + & NA & + & - & $\begin{array}{l}\text { failure } \\
\text { Liver }\end{array}$ & Gly848Ser/ Arg1096Cys \\
\hline $\mathrm{D}(30)$ & $24 \mathrm{~m}$ & + & + & - & + & + & NA & - & Ptosis & $\begin{array}{l}\text { failure } \\
\text { Liver }\end{array}$ & Ala467Thr/ Ser1095Arg \\
\hline$E(30)$ & $7 \mathrm{~m}$ & + & + & - & + & + & NA & + & NA & failure & \\
\hline
\end{tabular}

m: months, NA: not available, +: present, - : absent. 
Table 3. Comparison between patients with MCHS and Alpers phenotypes included in the study cohort

\begin{tabular}{lcccc}
\hline Ginical and laboratory findings & \multicolumn{2}{c}{ MaHS } & \multicolumn{2}{c}{ Apers } \\
\hline & & & & \\
Perinatal abnormality & $3 / 6$ & $(50 \%)$ & $8 / 19$ & $(42 \%)$ \\
Hypotonia & $6 / 6$ & $(100 \%)$ & $15 / 17$ & $(88 \%)$ \\
Developmental delay & $6 / 6$ & $(100 \%)$ & $16 / 19$ & $(84 \%)$ \\
Seizures & $0 / 6$ & $(0 \%)$ & $19 / 19$ & $(100 \%)$ \\
Liver dysfunction & $6 / 6$ & $(100 \%)$ & $19 / 19$ & $(100 \%)$ \\
Renal tubular dysfunction & $3 / 6$ & $(50 \%)$ & $0 / 19$ & $(0 \%)$ \\
Ophthalmological disorders & $4 / 6$ & $(67 \%)$ & $7 / 16$ & $(37 \%)$ \\
Respiratory chain enzyme deficiency & $5 / 5$ & $(100 \%)$ & $6 / 9$ & $(67 \%)$ \\
\hline
\end{tabular}


Supplementary file 1. Summary of the study cohort

\begin{tabular}{|c|c|c|c|c|c|c|}
\hline Case study Number & Diagostic center & Ethnicity & Age of onset ( months) & Age at death( months) & Phenotype & Mutations (polymorphism) \\
\hline 1 & Norway & Northern European & 11.23 & 12.9 & Alpers & p.Ala467Thr/p.Gly303Arg \\
\hline 2 & Norway & Northern European & 23.5 & 105.43 & Alpers & p.Ala467Thr/p.Gly303Arg \\
\hline 3 & Norway & Northern European & 5.83 & 8.17 & Alpers & p.Ala467Thr/p.Gly848Ser \\
\hline 4 & Norway & Northern European & 15.17 & 20.03 & Alpers & p.Ala467Thr/p.Gly303Arg \\
\hline 5 & Norway & Northern European & 12.07 & 18.87 & Alpers & p.Trp748Ser/ p.Gly1052Asp \\
\hline 6 & Norway & Northern European & 15.17 & 18.8 & Alpers & p.Trp748Ser/ p.Arg807Cys \\
\hline 7 & Norway & Northern European & 12.53 & 15.8 & Alpers & p.Trp748Ser/p.Arg807Cys \\
\hline 8 & Norway & Northern European & 11.87 & 15.87 & Alpers & p.Gly303Arg/p.Ala467Thr \\
\hline 9 & UK & Northern European & 1.47 & 13.87 & Alpers & p.Ala467Thr/p.Thr914Pro \\
\hline 10 & UK & Northern European & 16.87 & Alive & Alpers & p.Ala467Thr/ C.3483-4_3497 del \\
\hline 11 & UK & Northern European & 11.47 & 13.9 & Alpers & p.Ala467Thr/p.Gly848Ser \\
\hline 12 & UK & Middle East/UAE & 13.83 & Alive & Alpers & p.Arg1096Cys/p.Arg1096Cys \\
\hline 13 & UK & Northern European & 8.53 & 11.77 & Alpers & p.Arg807His/p.Gly1052Ser \\
\hline 14 & UK & Northern European & 80.43 & NA & Alpers & p.Ala467Thr/p.Ala467Thr \\
\hline 15 & UK & Northern European & 2.03 & 8.97 & Alpers & $\begin{array}{l}\text { p.His1110Tyr+ (p.Gln1236His) / } \\
\text { p.Trp748Ser+(p.Glu1143Gly) }\end{array}$ \\
\hline 16 & UK & Northern European & 4.77 & 5.33 & $\mathrm{MOHS}$ & $\begin{array}{l}\text { p.His1110Tyr+(p.Gln1236His)/ } \\
\text { p.Trp748Ser+(p.Glu1143Gly) }\end{array}$ \\
\hline 17 & UK & Northern European & 7 & 30.07 & $\mathrm{MOHS}$ & p.Arg232His/p.Gly848Ser \\
\hline 18 & UK & Northern European & 6.33 & 25.37 & $\mathrm{MOHS}$ & p.Arg232His/p.Gly848Ser \\
\hline 19 & UK & Cyprus & 3.33 & 5.37 & $\mathrm{MOHS}$ & p.Thr251lle+p.Pro587Leu/p.Glu1136Lys \\
\hline 20 & UK & Cyprus & 4.6 & 9.57 & $\mathrm{MOHS}$ & p.Thr251lle+p.Pro587Leu/p.Glu1136Lys \\
\hline 21 & UK & Pakistan & 0.93 & 1.47 & Alpers & p.Arg227Trp/p.Arg227Trp \\
\hline 22 & UK & Northern European & 0.93 & 6.03 & MOHS & p.Tyr831Cys)/p.His1134Arg \\
\hline 23 & UK & Northern European & 3.47 & Alive & Alpers & p.Gly848Ser/p.Lys498Thr (novel) \\
\hline 24 & UK & Northern European & 0.57 & 1.03 & Undassified & p.Tyr831Cys/p.His 1134Arg \\
\hline 25 & UK & Northern European & 36.7 & 68.47 & Alpers & p.Ala476Thr/p.Ala467Thr \\
\hline 26 & UK & Northern European & 18.27 & 32.03 & Alpers & p.Ala467Thr/p. Gly621Asp (novel) \\
\hline 27 & UK & Northern European & 2.83 & Alive & MNGIE & p.Arg232His/p.Gly848Ser \\
\hline
\end{tabular}

NA: not avilable, UAE: United Arab Emirates, MCHS: myocerebrohepatopathy spectrum, MNGIE: mitochondrial neurogastrointestinal encephalopathy 


\section{Supplementary file 2: POLG Respiratory chain enzyme activities}

\begin{tabular}{|c|c|c|c|c|c|c|c|c|c|}
\hline $\begin{array}{l}\text { Case } \\
\text { nr. }\end{array}$ & Phenotype & ComplexI & ComplexII & $\begin{array}{l}\text { Complex I:II } \\
\text { Ratio }\end{array}$ & Complex III & Complex II+III & ComplexIV & Comment & $\begin{array}{l}\text { Reference } \\
\text { range }\end{array}$ \\
\hline 1 & Alpers & \begin{tabular}{|l|}
0.024 \\
\end{tabular} & 0.034 & & 0.192 & & 0.144 & $\begin{array}{l}\text { Multiple enzyme } \\
\text { deficiencies }\end{array}$ & $a$ \\
\hline 3 & Alpers & 0.093 & 0.249 & 0.373 & & & 1.212 & $\begin{array}{l}\text { Isolated complex I } \\
\text { deficiency (low I:II) }\end{array}$ & $a$ \\
\hline 8 & Alpers & $t$ & & & & & & $\begin{array}{l}\text { Isolated complex I } \\
\text { deficiency }\end{array}$ & $a$ \\
\hline 11 & Alpers & \begin{tabular}{|l|}
0.151 \\
\end{tabular} & & & & 0.084 & 0.018 & Normal & $b$ \\
\hline 12 & Alpers & 0.156 & & & & 0.079 & 0.004 & $\begin{array}{l}\text { Isolated complexIV } \\
\text { deficiency }\end{array}$ & $\mathrm{b}$ \\
\hline 13 & Alpers & 0.126 & & & & 0.159 & 0.026 & Normal & $b$ \\
\hline $13^{*}$ & Alpers & 0.081 & & & & 0.031 & 0.007 & $\begin{array}{l}\text { Multiple enzyme } \\
\text { deficiencies }\end{array}$ & C \\
\hline 14 & Alpers & 0.126 & & & & 0.159 & 0.026 & Normal & $\mathrm{b}$ \\
\hline 15 & Alpers & \begin{tabular}{|l|}
0.146 \\
\end{tabular} & & & & 0.133 & 0.020 & Normal & $\mathrm{b}$ \\
\hline 17 & MaHS & 0.097 & & & & $<0.001$ & 0.006 & $\begin{array}{l}\text { Multiple enzyme } \\
\text { deficiencies }\end{array}$ & $\mathrm{b}$ \\
\hline 18 & MCHS & 0.061 & & & & 0.019 & 0.008 & $\begin{array}{l}\text { Multiple enzyme } \\
\text { deficiencies }\end{array}$ & $\mathrm{b}$ \\
\hline 19 & MOHS & 0.058 & & & & 0.014 & 0.004 & $\begin{array}{l}\text { Multiple enzyme } \\
\text { deficiencies }\end{array}$ & $\mathrm{b}$ \\
\hline 20 & MCHS & 0.091 & & & & 0.084 & 0.011 & $\begin{array}{l}\text { Multiple enzyme } \\
\text { deficiencies }\end{array}$ & $\mathrm{b}$ \\
\hline 21 & Alpers & 0.157 & & & & 0.070 & 0.023 & Normal & $\mathrm{b}$ \\
\hline$a$ & $\begin{array}{c}\text { Reference range } \\
\text { (Norway cases } \\
\text { muscle) }\end{array}$ & $0.104 \pm 0.036$ & $0.145 \pm 0.047$ & $0.52-0.95$ & $0.554 \pm 0.345$ & & $1.124 \pm 0.511$ & & $a$ \\
\hline b & $\begin{array}{l}\text { Reference range } \\
\text { (UK cases muscle) }\end{array}$ & $0.104-0.268$ & & & & $0.040-0.204$ & $0.014-0.034$ & & $\mathrm{~b}$ \\
\hline C & $\begin{array}{l}\text { Reference range } \\
\text { (UK cases liver) }\end{array}$ & $0.054-0.221$ & & & & $0.057-0.204$ & $0.011-0.031$ & & $\mathrm{C}$ \\
\hline
\end{tabular}

† Reported as abnormal, no figures available; *liver biopsy 